\title{
DESIGNING FOR SUSTAINABLE BEHAVIOUR PRACTICES IN CONSUMERS: A CASE STUDY ON COMPOSTABLE MATERIALS FOR PACKAGING
}

\author{
R. Santi ${ }^{1, \bigotimes}, G$. Elegir ${ }^{2}$ and B. Del Curto ${ }^{1,3}$ \\ ${ }^{1}$ Politecnico di Milano, Italy, ${ }^{2}$ Innovhub-SSI, Italy, ${ }^{3}$ Consorzio Nazionale di Scienza e Tecnologia dei Materiali, Italy \\ $\bigotimes$ romina.santi@polimi.it
}

\begin{abstract}
When assessing the sustainability of a product, an ideal life cycle is considered which could include the "Use" and "End of Life" phases. Does human behaviour affect the environmental sustainability? This paper intends to propose a methodological framework for assessing sustainable behavioural scenarios. The framework will be then developed in a specific case study on Compostable Single Use Products (CSUPs), with the aim of designing the identity of compostable materials for packaging in order to guide consumers to behave in a sustainable way in CSUPs disposal phase.
\end{abstract}

Keywords: human behaviour, sustainable design, user-centred design, aesthetics, packaging

\section{Introduction}

Designers through materials, functions and shapes give life to objects, which generate actions, behaviours and ways of living of society. Therefore, designers can determine which kind of connection will trigger between the individual and the environment, between consumers and society trying to reach sustainable scenarios. Developing sustainable products, the role of designer is to combine the shape, the material and the semantic attributes of the product in order to "design" even the users' behaviour. Several authors have discussed how a product can influence users, for example guiding sustainable behaviours. The field of Design for Sustainable Behaviour (DfSB) investigates, at various levels, how to influence the sustainability impact of consumers' activities, through studying their attitudes and practices, developed over time and space (Boks et al., 2015; Lilley and Wilson, 2017). DfSB aims specifically on reducing the environmental impact caused by the way people interact with products (Lockton et al., 2008; Boks et al., 2015). This approach diverges from Life Cycle Design approach but is certainly related to it. The approach to product Life Cycle Design sets a series of strategies and design guidelines for the integration of environmental requirements in the development phases of a product (Vezzoli, 2016) and it is focused on the means of consumption (the product) instead of the practices involved in consumption itself. The behavioural aspect of the user plays a fundamental role in assessing the environmental impact of a product (Polizzi di Sorrentino et al., 2016). The way in which consumer interact with a product can produce a series of indirect effects that generate impacts on the overall potential environmental impact. Sometimes these indirect aspects are potentially more harmful than the impact of the product itself. Several life cycle assessment (LCA) studies present a contribution of the use phase at the level of 50-80\% of the overall life cycle impacts: this is the case e.g. of household electric devices (Hertwich and Roux, 2011). In the packaging sector, 
users' behaviour can have significant impacts if it is assumed that misuse of packaging can also lead to food losses (Wikström et al., 2016). Another important aspect is to understand how the packaging leads to the disposal phase and therefore to recycling, as the phase of disposal of the product is a highly impacting phase (Nemat et al., 2019; Wever et al., 2010). The knowledge on this topic may further help eco-designers to redesign products that are strategic to be used in the desired way. The data acquisition from qualitative and quantitative user analyses may bring the knowledge of misuses or wrong attitudes that can constitute a data base to be included in the LCA to build different scenarios (Daae and Boks, 2015a). When compiling an LCA, an ideal product life cycle is considered, which, in the case of a study "from cradle to grave" or "from cradle to cradle", includes the "Use" and "End of Life" phases. This ideal life cycle, however, may not reflect reality and therefore creates only utopian scenarios of products impact.

Through analysed literature, this study intends to propose a framework that can be useful to designers who intend to approach to DfSB discipline. In the present study a methodological framework for designing for the most sustainable behavioural scenario, based on the LCA approach has been proposed and discussed. The aim is to examine a case study such as that of compostable food packaging and analyze the context and the sustainability issues that depend on consumer behaviour. This will allow to find design approaches for environmental sustainability based on consumer scenarios. The role of packaging design in consumer disposal behaviour is a topic of research widely discussed in literature and reviewed by Nemat et al., 2019. Despite this, none of the reviewed interventions took the aesthetic and expressive-sensorial dimensions of the material as attribute to be managed in order to achieve long term sustainable disposal behaviours. The approach of this study is to frame solutions based on the materiality of the product, which represent a factor of high influence on the acceptance and recognition of materials in the social context, with ample communication possibilities.

\section{Materials design}

The first example of "Material Design" in design culture has been "Neolite" (Manzini and Petrillo, 1991) which was the adventurous heterogeneous plastic recycled in search of an "own identity". From here came the concept of materials soft quality design in order to determinate materials identity. Thus, the design of materials was born: an activity that at the beginning of the eighties was still a testing ground and that today is, to all effects, a new territory of design (Manzini, 1996). The subject of material design then intersects for the first time directly with the theme of sustainability and opens debates on "second material", informing citizens for the first time how the new production processes of sustainability imply new behavioural models and sustainable materials. Materials act as a key element to transfer knowledge, skills and creativity. In that way, the material represents the medium through which industrial designers realize shapes and establish different formal languages (Ashby and Johnson, 2002; Manzini, 1986). As a result, the history of product design is closely linked to the evolution of materials science (Del Curto et al., 2015; Karana and Hekkert, 2010). By manipulating the "materiality" of an object, designers can satisfy functions and performances, characterize the product experience and to express a specific emotional and aesthetical intention (Ashby and Johnson, 2002; Van Kesteren et al., 2007). Academic studies focused on understanding better the interaction between materials and users through our senses. During user-product interaction, indeed, the senses explore the product's surface, which primarily convey visual and tactile stimuli, eliciting perceptions associated to the product (Bergmann Tiest, 2010; Fleming, 2014; Wongsriruksa et al., 2012; Zuo et al., 2001). Del Curto et al. (2010) contributed to investigate how manufacturing processes and finishing technologies can affect the soft qualities of surfaces, also called sensory-expressive characteristics of materials. By providing practical tools ("the project cards"), the aim of the overmentioned study is to present a guideline to design finishing soft qualities in a structured way, linking materials and processing technologies with visual and tactual results that can be obtained on a surface. On the other hand, Karana and Hekkert (2010) explored the concept of intangible aspects of materials (meaning, associations, etc.) that can be appropriately selected by the designer in order to express his intentions on the project. In the material and finishes selection for the industrial context, the integration of aesthetical considerations is connected to the need of associating subjective deliberations on the project with measurable supporting data (Piselli et al., 2016, 2017). Sensory analysis techniques (Bacci et al., 2012; Faucheu et al., 2015; de Morais and Pereira, 2015; Ndengue et al., 2016), commonly used in the food 
and beverage, textile and cosmetic industry, have been recognized as possible practical tools to help designers in exploring their Colour Materials and Finishes (CMF) choices.

\section{Methodology: finding sustainable behavioural scenarios}

When designing for sustainability, designers might come to a crossroads and must evaluate whether the product designed through eco-design strategies or material replacement is more sustainable than the existing solution. In the following methodology explanation has been assumed that through an LCA study, that the new proposal A is environmentally preferable than the previous one (B) as shown in Figure 1a. In this case it would seem obvious to opt for a replacement, but the methodology intends integrate into the evaluation the consumer behavioural variable. The framework showed in Figure 1 integrates the effects that the consumer can have in determining the environmental impact of the product. Imagine for example that the same product A of the previous case is questioned. Consumers' studies highlight that the way of use and abuse of a product could lead to an indirect effect not previously considered in the LCA. For example, a variation in the use or disposition phase must be identified and associated with an indirect effect on the impact of the product, such as food waste impact, decrease in efficiency, decrease in lifetime, waste of water etc.

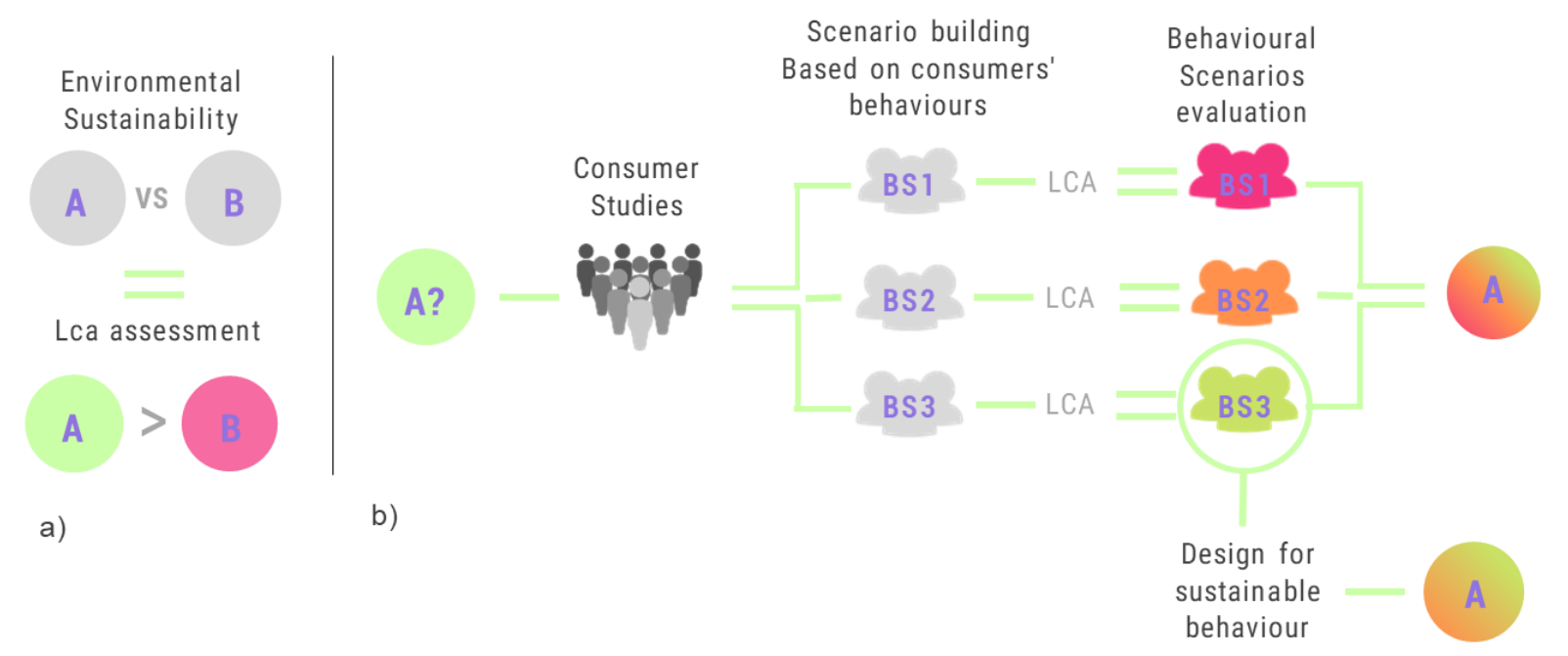

Figure 1. Methodological framework proposed for DfSB integration in LCA analysis

Quantitative studies can be assessed using for example data from consumer associations or can be obtained through user analysis methods belonging to the "User centred design" (Daae and Boks, 2015b). For example, consumers use to do not reuse products or use them in the wrong way, leave some food in packaging before disposition. Each of these circumstances therefore helps to build different behavioural scenarios based on quantitative and qualitative data provided by the previous study. Then, for each scenario evaluation, a different LCA must be assessed. In compiling these LCAs, the system must keep the same boundaries, the same functional unit as the one already built, and which included the use and end of life phase. Therefore, every Behavioural Scenario (e.g. BS1, BS2, BS3 ...) will be analysed in parallel and different potential impacts of the product will be calculated. In case of availability of quantitative data would be possible to integrate then in order to create a probabilistic scenario interpretation. For example, an LCA built on a scenario (BS1) could be even worse than the initial case B, maybe that scenario was the most probable to occur. Instead the best scenario could have only a low percentage of cases (e.g. BS3 10\%) and so it is possible to create a series of understandings that contribute to a probabilistic view of the interpretation phase of the LCA. Therefore, the definitive impact brings together the best and worst "behavioural case" of the indirect effect of the product consumption. The redesign through the strategies of Design for Sustainable Behaviour (Lilley and Wilson, 2017) should aim to establish in the user the behaviour that leads to a minor impact (e.g. BS3) going to increase the probability of that scenario as shown in Figure 1b. In this way, the focus for redesigning is through those attributes of the product that can guide the user to the right behaviour (Zafarmand et al, 2003; Lee and Xu, 2005; Krishna et al., 2017). After 
a subsequent user analysis and verification, it can be assumed that DfSB has lowered the overall potential impact of the product (A).

\section{Case study: compostable single use plastics (CSUPs)}

In the last 20 years, a great concern arose around the topic of plastic materials derived from fossils; one of the major macro phenomena studied by the scientific community is the marine litter. The EU Plastics Strategy (ICF and Eunomia Research \& Consulting, 2018) aims to find alternative materials in substitution to fossil-based towards an effective Circular Economy approach/practice. Single Use Plastics (SUPs), for example food related products, are progressively being replaced on the market with products in bio-based compostable materials. There are two main advantages of bio-based compostable products compared to their conventional versions: the use of biomass instead of fossil resources and the digestion in industrial composting facilities, which is an additional property of some types of bioplastics (European bioplastics, 2017). In the literature there are a number of comparative LCAs for which the new compostable packaging have been assessed more sustainable than fossil-based ones (Lee and $\mathrm{Xu}, 2005$; Madival et al., 2009; Grigale et al., 2010; Gironi and Piemonte, 2011; van der Harst et al., 2014). Due to environmental, technical and legislative issues, compostable SUPs are multiplying on the market. Despite this, their peculiar end-of-life options such as composting, mechanical recycling and anaerobic digestion are not yet optimized in many European countries such as Italy, where their incineration with energy recovery is an option much more present. The dilemma about composting or not is already opened. A series of articles has reported how composting is not significantly environmentally preferable over energy recovery (incineration), in contradiction with EU waste hierarchy (Hermann et al., 2011; Piemonte, 2011; Papong et al., 2014; van der Harst et al., 2014; Rossi et al., 2015). However, the study about end of life solutions for packaging heavily contaminated with wet food residues could lead to substantially different conclusions focusing on composting as the preferable end-of-life option. The resulting mixed homogeneous waste (containing food waste and compostable plastic) can be recycled by composting with a lower environmental impact than the previous plastic solution (Razza et al., 2009).

\subsection{Method application: A sustainable behavioural scenario for CSUPs}

In this section will be presented the framework outlined in Figure 1 presented in the selected case study. From literature reviewed in Paragraph 4, it was assumed that food SUPs dedicated to catering, events or "out of home" application are more sustainable if they are made of bio-based compostable material (instead of fossil-based plastics) (Figure 2a) and are addressed to the organic fraction of the recycling system (e.g. compostable cutlery, plates, food containers, beverage cups etc...). Food related Compostable SUPs (CSUPs) solutions were quickly developed by companies to offer as soon as possible bioplastics products alternatives to those denied by EU directives. These products have revealed a fundamental weakness: they are often indistinguishable from the fossil-based ones by the consumers. This unrecognizability leads to an indirect effect: user can make mistakes in waste sorting, having a corrupted perception of the material. By mistaking the disposal at end of life, user can even let the CSUPs in other waste collection (e.g. paper or plastic). The compostability will be impaired and their life cycle is no longer circular. Then CSUPs do not exploit their compost-ability and could go to contaminate other types of recycling.

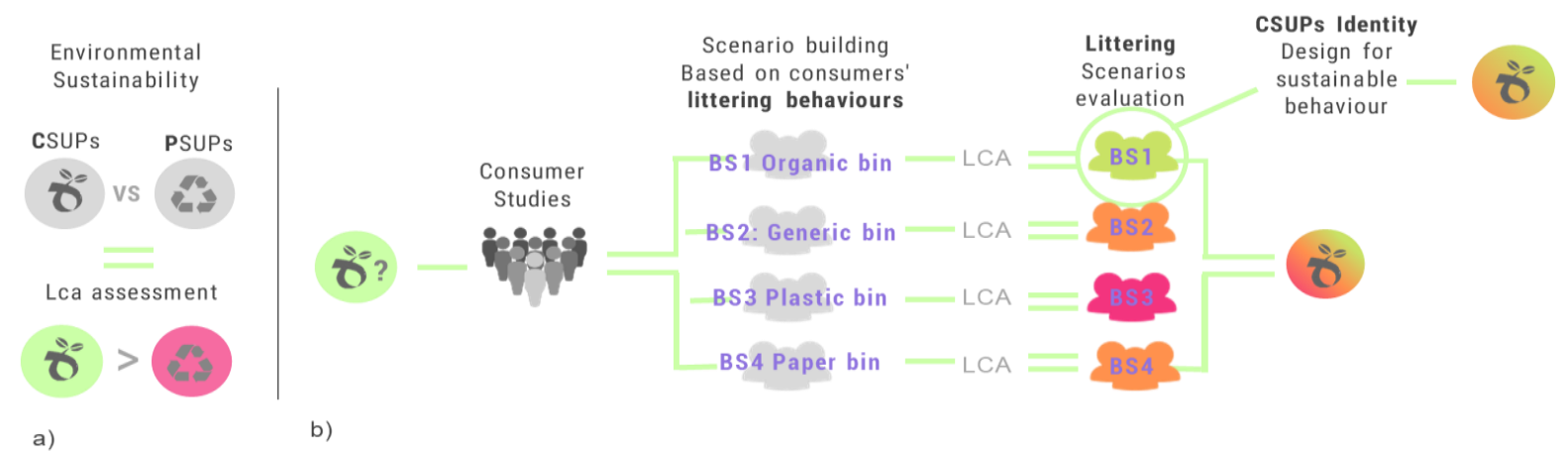

Figure 2. Methodological framework applied to the case study of CSUPs 
Behavioural Scenarios are then constructed from consumer's studies:

- BS1: CSUPs are disposed in the generic fraction and follow the path of energy recovery for packaging and the possibly food losses related;

- BS2: CSUPs are disposed in the organic fraction of collection and they are composted in industrial facilities;

- BS3: CSUPs are disposed by consumers in the plastic waste stream. In this case, a measurement of the indirect impact must be destined to the contamination of the recycling chain by food waste and bioplastics. From an analysis of the Italian system of waste collection, it is assumed that, generally, CSUPs are not recognized by plastic selection automatic systems and then discarded. In the case of plastic recycling from household waste, this discarded compostable bioplastic waste will be incinerated with energy recovery.

- BS4: CSUPs are collected with the paper fraction. In this case, the waste is brought firstly to the dilution and pulping process. CSUPs because no water-soluble are discarded after this stage together with coarse waste, which is brought to incineration. In those circumstances, food scraps and compostable materials can generate contaminations and interruptions in operation of paper mills.

In the present study it can be reported by literature based on Razza et al. (2009) that identifies as the most sustainable scenario BS1, other scenarios have a higher environmental impact. The extent of diversity of the impact of the second and third scenarios comes from the different contamination effect that paper or plastic recycling chain can have. By the acquisition of in-depth quantitative data could also be possible to implement a probabilistic view. The new CSUPs should be designed in an active way driving their recognition and disposal in the organic fraction. To do this, product design must follow those perceptual attributes of compostable materials, or at least avoid following the perceptive attributes of plastics or paper ones (Figure 2b). It is therefore relevant that the CSUPs have their own characterization factors. These strategies can be identified by user analysis, subsequently verified and finally achieve a lower environmental impact thanks to the adoption of DfSB approach.

\subsubsection{Consumers' studies and preliminary results}

For better understanding consumers' behaviours dynamics, different studies have been designed and conducted at the authors' home institution. A preliminary study was focused on tactile and visual appearance of three commons compostable packaging material samples. Twenty-six participants evaluated different materials attributes on a 5-point scale: renewability, natural-look, perceived quality, cost. Multiple-choice answers were used to detect waste stream materials association. A phase of free association of adjectives, attributes and association of an imaginary of products made in that material was also performed. Samples have not been univocally associated to a single material class and were perceived as hybrids. From this study, emerged the need for a new experimental research investigating the gestures and senses involved in packaging exploration before disposal, the perceptual attributes of different packaging materials and the possible correlation between such attributes and the related waste stream. The consumer study named "where do you throw it" has been designed in different observations asking to consumers to behave as in reality, when they have to choose how to dispose a product, leaving the users free to express their thoughts. One product at a time, for a total of fifteen, was presented to the assessor that, through a spontaneous sensorial analysis, was asked to place the product in a specific bin. Through an ad-hoc designed app for data acquisition, it was possible to take note of the type of interaction that the consumer carried out. Then, bins have been emptied, products thrown in the same bin have been put in front of it and each user was asked to perform a survey to predict the correctness of their choices. As final step, consumers were asked to associate aesthetic attribute associations to the products thrown in the same waste stream. At the end of this session, the real destination of the SUPs was then revealed to each user and their reactions were collected. In Figure 3 is shown the path of each SUP taken as sample, starting from its denomination, the material that is made of and to follow, the disposal choice done by consumers. The plastic products were the most recognized by consumer, to follow those destined to paper recycling and finally the single-use products destined for organic fraction. 


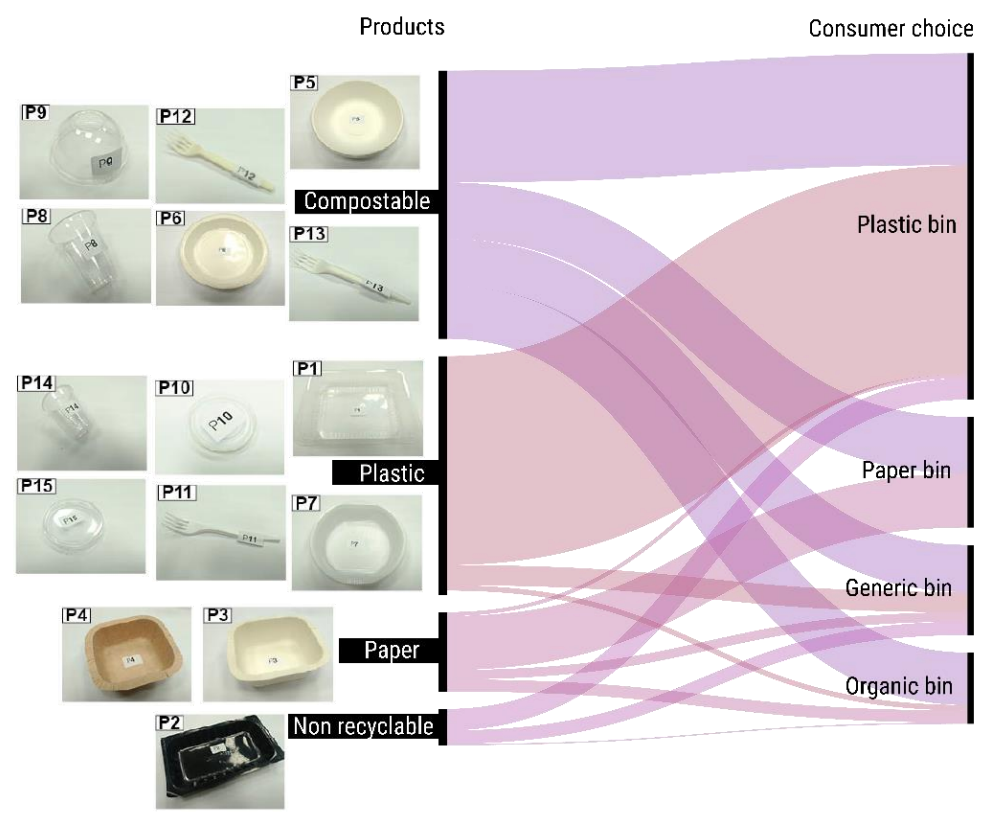

Figure 3. How do consumers dispose plastic, paper and compostable products?

These have been disposed for the larger amount in the plastic chain and then uniformly to the other collections. Consumers were also asked to answer to the question "What factors influenced the choice of disposal for each waste stream?". The possible attributes were proposed to consumers and they could add more free thoughts to the questionnaire. In Figure 4a are summarized the results: for each attribute, the association with a specific class of materials end of life. Preliminary results show how transparency, much sought after in food packaging products, is a misleading factor for CSUPs, but is the predominant factor for plastics.

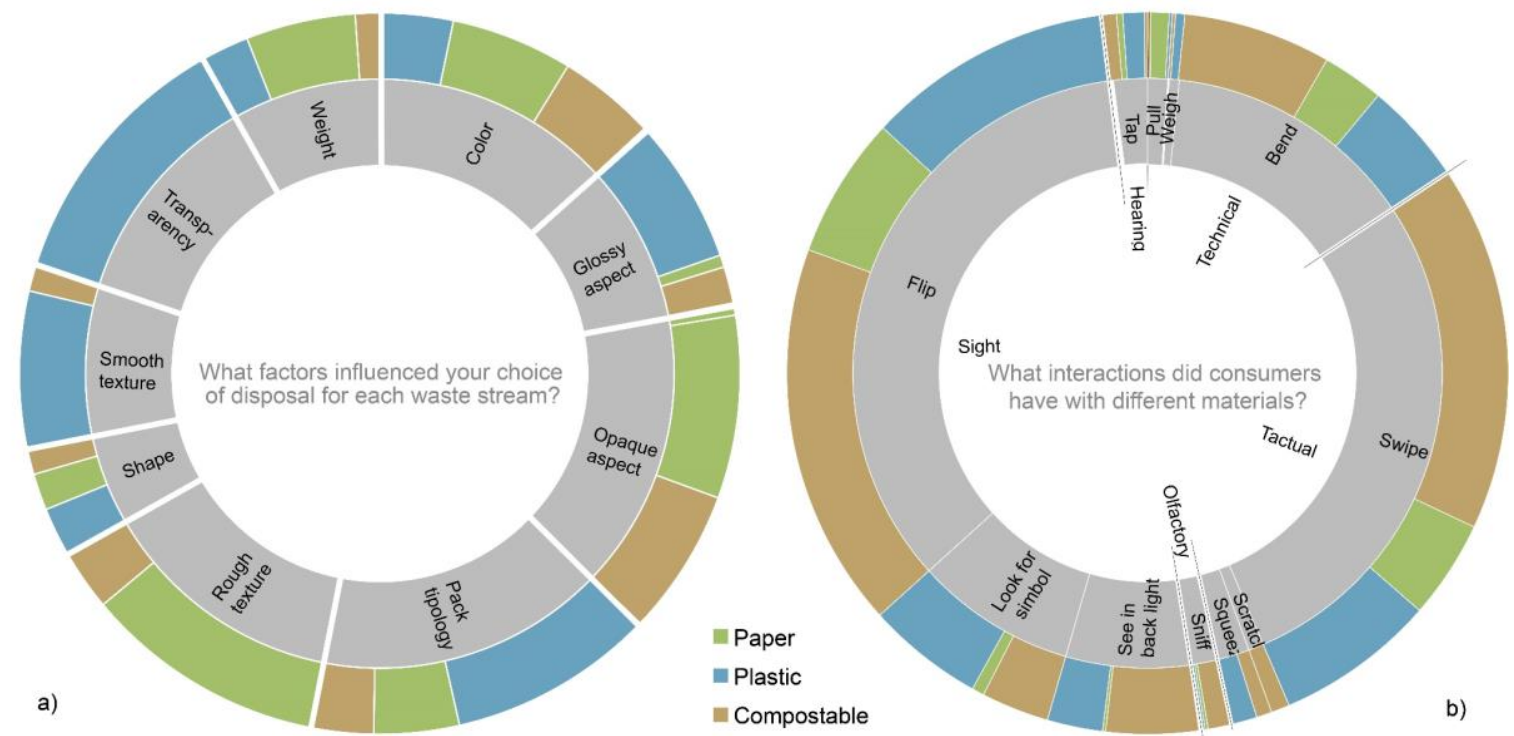

Figure 4. a) Data elaboration of the test results representing materials attribute association; b) gestures and sensed involved in the consumer-product interaction

The same could be affirmed for the glossy aspect and the smooth texture associated to plastic products. Moreover, compostable products don't have a specific attribute association but the colour (sight), texture (touch) and smell can be possible sensory channels to be explored in designing with compostable bioplastics. The second results analysis involved the gestures and so the senses involved 
in the consumer-products interaction. In Figure $4 \mathrm{~b}$ is shown the distribution of the gestures categorized by the sense involved for the exploration. While compostable materials resulted the products more sensorially explored by sight, touch and technical exploration moreover, plastic and paper products have been less explored. Could be also noticed that consumers have involved also the olfactory sense in the CSUPs product exploration. The sense more involved is resulted the sight and, the most frequent gesture turned out to be to flip the product in order to explore more and more the material and even look for symbols or see it in back light. Four CSUPs, the ones that were multimaterial (e.g. paper-based bio-coated) have involved the users in a greater way, they seem ambiguous and hybrid. Transparent CSUPs have not been sensorially investigated and have been disposed together with plastic materials in most cases relying on the view and pre-knowledge of the product archetype.

\subsubsection{Designing compostable materials for sustainable behaviour}

Many designers admit that they find it difficult to find the right strategy to meet consumer expectations, not having a clear idea of how customers' propensity towards sustainability evolves. The food packaging sector is revolutionizing consumer labelling systems and promoting educational campaigns, municipal, local and international measures. Bio-based compostable bioplastics can offer some distinct effects, for example, the natural and woody look and bio feeling. Surface imperfections, fibres visibility and random inclusions can be appreciated in terms of visual attributes. Consumer that chooses products made from these materials may have environmental safety feeling of having in hands a product that won't be harmful for the environment after disposal. Masterbatches and additive for compostable bioplastics are increasing on the market. They could represent key products in order to design the Colour Material Finishing (CMF) attributes of compostable bioplastics. Starting from the preliminary results showed in the previous paragraph, have been extracted the misleading attributes for CSUPs. From that, a set of variables have been formulated in order to explore the compostable bioplastics identity. These variables are represented by colour, glossiness, inclusions, textures and transparency. Seventeen compostable materials samples showed in Figure 5 have been designed and produced by a lab-scale technique.

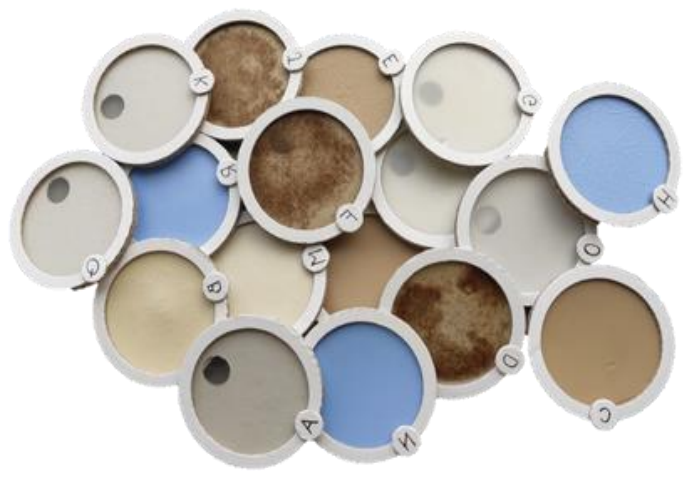

Figure 5. Compostable materials samples exploring the CSUPs identity

Variables has been declined into attributes thanks to the possibility to manage them by adding to a compostable matrix a set of masterbatches and inclusions as can be seen in Figure 6. In order to design the right materials experience, a series of textures, translucencies and glossiness have been also selected proposing a catalogue of compostable materials identities. This approach has the objective to handle the aesthetic and sensory attributes of compostable materials in order to guide the correct material-littering association. This samples will be subject to consumer judgment in order to keep responses and expanding the set of variables to be managed in further studies. From the extensive review of Nemat et al., 2019 about the role of food packaging design in consumer recycling behaviour, there are no evidence of papers that have focused on the aesthetic and expressive sensorial dimension of the materials. Instead, it is an important means of communication, which can be designed to convey 
information to consumers. In the present study, the priority will be given to the communicative power of materials, before the label, shape, mass, weight, dimensions, symbols, verbal signals and so on.

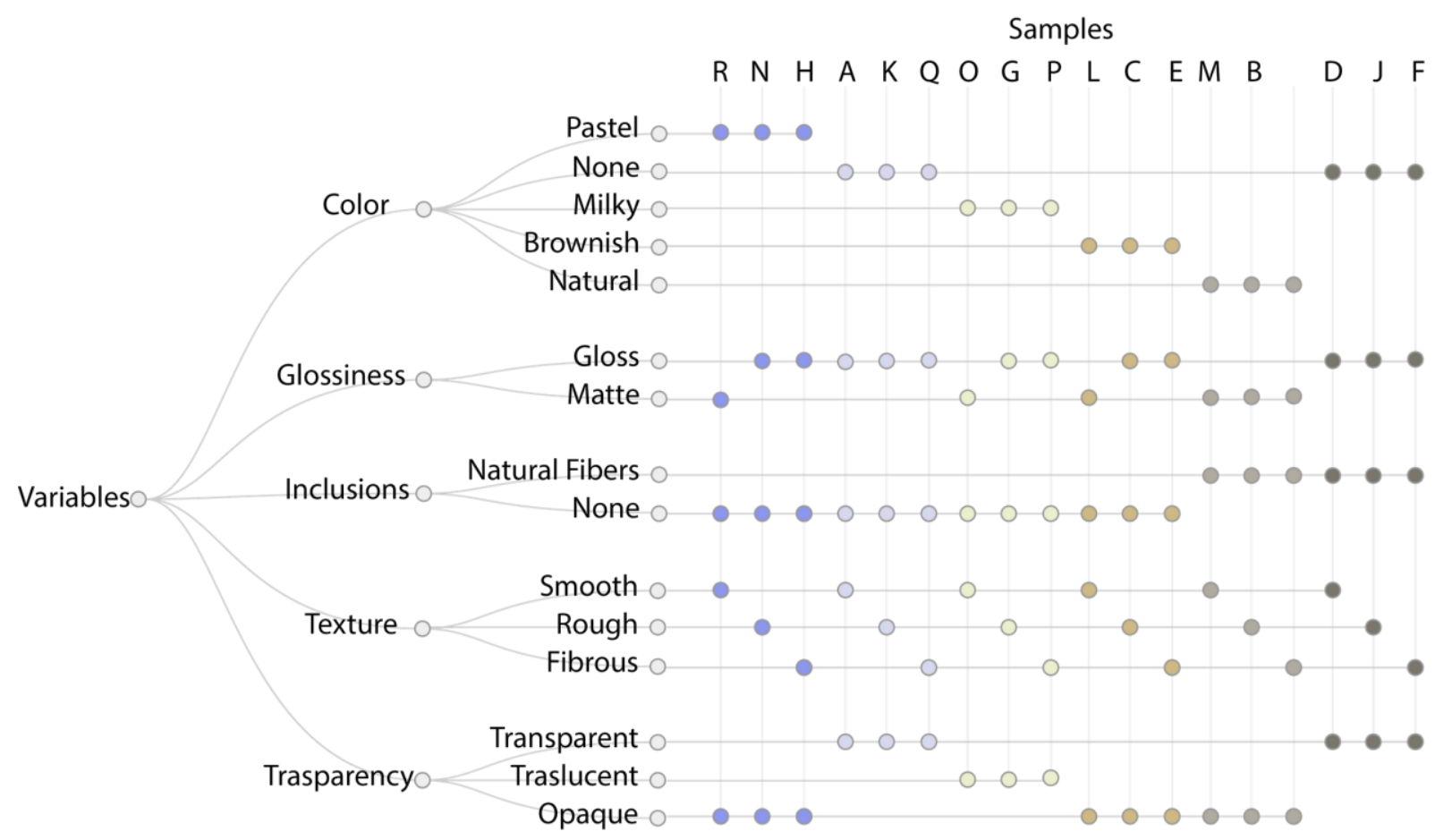

Figure 6. Set of variables managed in designing for CSUPs

\section{Conclusions}

Users' behaviour is an active and decisive factor when assessing the environmental impact of a product. This study placed the user at the centre of the system to identify the causes and to highlight the indirect impact that a wrong product design can cause. In order to introduce sustainable alternatives, it is important not only to refer to the eco-design guidelines but also to drive the sustainable behaviour of consumers. A product designed to be more sustainable than an alternative can then be discussed by focusing the analysis on the consumer, this aspect can have a major impact on the LCA of products. DfSB is a field of great importance in the modern panorama, where a great effort is required for design sustainable product and systems. Even if companies are engaging in the proposal of new and sustainable materials solutions, there is still a lack of sensitivity regarding the care of aesthetics, the study of trends and consumer choices that is often caught off guard by the novelty of the proposals. For this the aesthetic inspiration of Do-It-Yourself materials, combined with the creation of a new and more recognizable identity of these products, could be the key to the establishment of a new economy. The aesthetic and formal immaturity of bioplastic products currently on the market is often translated by the consumer eyes in poor quality, low durability and minor performances. The expressive-sensorial dimension of the product is fundamental in order to establish a relationship that can have a great influence on the society's consumption model. The experience with compostable products should be refined and taken towards a perceived "natural" and "high quality" look, as an expression of consumer responsibility and ethics. The research pushes environmental issues with a look at the circular economy, waste disposal and the ethical and aesthetical sense of "compostable". The study, based on a particular social and disposal context, can have a limitation by changing the social context of analysis. Different cultures have different meaning of materials within them and before tackling a solution in this sense, the context must be studied closely. The study intends to begin to approach fields that seem to be distinct so far: Design for Sustainable Behaviour trough Materials Design as a means of communication to the consumer. 


\section{References}

Ashby, M. and Johnson, K. (2002), Materials and Design: The Art and Science of Material Selection in Product Design, edited by Butterworth-Heinemann, Oxford.

Bacci, L. et al. (2012), Sensory evaluation and instrumental measurements to determine tactile properties of wool fabrics.

Bergmann Tiest, W.M. (2015), “Tactual perception of liquid material properties”, Vision Research, Vol. 109 No. PB, pp. 178-184. https://doi.org/10.1016/j.visres.2014.08.002

Boks, C., Lilley, D. and Pettersen, I.N. (2015), "The future of design for sustainable behaviour, revisited", EcoDesign 2015 International Symposium.

Del Curto, B., Fiorani, E. and Passaro, C. (2010), La Pelle Del Design. Progettare La Sensorialità, Lupetti, Milano.

Del Curto, B., Marano, C. and Pedeferri, M. (2015), Materiali per Il Design, Second Edi., Casa Editrice Ambrosiana, Milano.

Daae, J. and Boks, C. (2015a), "Opportunities and challenges for addressing variations in the use phase with LCA and Design for Sustainable Behaviour", International Journal of Sustainable Engineering, Vol. 8 No. 3, pp. 148-162. https://doi.org/10.1080/19397038.2015.1010630

Daae, J. and Boks, C. (2015b), "A classification of user research methods for design for sustainable behaviour", Journal of Cleaner Production, Elsevier Ltd, Vol. 106, pp. 680-689. https://doi.org/10.1016/j.jclepro. 2014.04.056

European bioplastics. (2017), What are bioplastics? Material types, terminology, and labels - an introduction Bioplastics.

Faucheu, J. et al. (2015), "Experimental Setup for Visual and Tactile Evaluation of Materials and Products Through Napping ® Procedure", Proceedings of the 20th International Conference on Engineering Design (ICED 15), Vol. 1: Design for Life, No. July, pp. 1-10.

Fleming, R.W. (2014), "Visual perception of materials and their properties", Vision Research, Elsevier Ltd, Vol. 94, pp. 62-75. https://doi.org/10.1016/j.visres.2013.11.004

Gironi, F. and Piemonte, V. (2011), "Bioplastics and petroleum-based plastics: Strengths and weaknesses", Energy Sources, Part A: Recovery, Utilization and Environmental Effects, Vol. 33 No. 21, pp. 1949-1959. https://doi.org/10.1080/15567030903436830

Grigale, Z. et al. (2010), "Biodegradable Packaging from Life Cycle Perspective", Scientific Journal of Riga Technical University Material Science and Applied Chemistry, Vol. 21, pp. 90-96.

van der Harst, E., Potting, J. and Kroeze, C. (2014), "Multiple data sets and modelling choices in a comparative LCA of disposable beverage cups", Science of the Total Environment, Elsevier B.V., Vol. 494-495, pp. 129143. https://doi.org/10.1016/j.scitotenv.2014.06.084

Hermann, B.G. et al. (2011), "To compost or not to compost: Carbon and energy footprints of biodegradable materials' waste treatment", Polymer Degradation and Stability, Elsevier Ltd, Vol. 96 No. 6, pp. 1159-1171. https://doi.org/10.1016/j.polymdegradstab.2010.12.026

Hertwich, E.G. and Roux, C. (2011), "Greenhouse Gas Emissions from the Consumption of Electric and Electronic Equipment by Norwegian Households", Environmental Science \& Technology, American Chemical Society, Vol. 45 No. 19, pp. 8190-8196. https://doi.org/10.1021/es201459c

ICF and Eunomia Research \& Consulting. (2018), Assessment of Measures to Reduce Marine Litter from Single Use Plastics.

Karana, E. and Hekkert, P. (2010), "User-Material-Product interrelationships in attributing meanings", International Journal of Design.

Van Kesteren, I., Stappers, P. and De Bruijn, S. (2007), "Defining user-interaction aspects for materials selection: three tools", In: P.U. \& S.I.H. (Ed.), Design Inquiries, The Nordic Design Research Conference, pp. $1-10$.

Krishna, A., Cian, L. and Aydınoğlu, N.Z. (2017), "Sensory Aspects of Package Design”, Journal of Retailing, Vol. 93 No. 1, pp. 43-54. https://doi.org/10.1016/j.jretai.2016.12.002

Lee, S.G. and Xu, X. (2005), "Design for the environment: life cycle assessment and sustainable packaging issues", International Journal of Environmental Technology and Management, Vol. 5 No. 1, pp. 14. https://doi.org/10.1016/j.ecoleng.2013.07.039

Lilley, D. and Wilson, G.T. (2017), "Design for Sustainable Behaviour", In: Chapman, J. (Ed.), Routledge Handbook of Sustainable Product Design, Routledge, Abingdon, pp. 127-144.

Lockton, D., Harrison, D. and Stanton, N. (2008), "Making the user more efficient: Design for sustainable behaviour", International Journal of Sustainable Engineering, Vol. 1 No. 1, pp. 3-8. https://doi.org/10.1080/ 19397030802131068 
Madival, S. et al. (2009), "Assessment of the environmental profile of PLA, PET and PS clamshell containers using LCA methodology”, Journal of Cleaner Production, Elsevier Ltd, Vol. 17 No. 13, pp. 1183-1194. https://doi.org/10.1016/j.jclepro.2009.03.015

Manzini, E. (1986), The Material of Invention: Materials and Design, Arcadia Ed., Milano.

Manzini, E. and Petrillo, E. (1991), Neolite-Metamorfosi delle plastiche, Milano, Edizioni Domus Academy.

Manzini, E. (1996), "Design dei materiali", In: Branzi, A. (Ed.), Il design italiano 1964-2000, Milano, Mondadori Electa.

de Morais, I.C. and Pereira, A.F. (2015), "Perceived Sensory Characteristics of Wood by Consumers and Trained Evaluators", Journal of Sensory Studies, Vol. 30 No. 6, pp. 472-483. https://doi.org/10.1111/ joss. 12181

Ndengue, J.D. et al. (2016), Tactile Perception and Friction-Induced Vibrations: Discrimination of Similarly Patterned Wood-Like Surfaces, Vol. 9 No. X.

Nemat, B. et al. (2019), "The role of food packaging design in consumer recycling behavior-a literature review", Sustainability (Switzerland), Vol. 11 No. 16, MDPI AG, 01-Aug-2019. https://dx.doi.org/10.3390/ su11164350

Papong, S. et al. (2014), "Comparative assessment of the environmental profile of PLA and PET drinking water bottles from a life cycle perspective", Journal of Cleaner Production, Vol. 65, pp. 539-550. https://doi.org/ 10.1016/j.jclepro.2013.09.030

Piemonte, V. (2011), "Bioplastic Wastes: The Best Final Disposition for Energy Saving”, Journal of Polymers and the Environment, Vol. 19 No. 4, pp. 988-994. https://doi.org/10.1007/s10924-011-0343-z

Piselli, A. et al. (2017), "Effect of wear from cleaning operations on sintered ceramic surfaces: Correlation of surface properties data with touch perception and digital image processing", Wear, Vol. 390-391, pp. 355366. https://doi.org/10.1016/j.wear.2017.09.003

Piselli, A., Simonato, M. and Del Curto, B. (2016), "Holistic approach to materials selection in professional appliances industry”, In: Marjanović, D., Štorga, M., Pavković, N., Bojčetić, N. and Škec, S. (Eds.), Proceedings of the 14th International Design Conference, DESIGN2016, Vol. DS 84, The Design Society, Cavtat, Dubrovnik, pp. 865-874.

Polizzi di Sorrentino, E., Woelbert, E. and Sala, S. (2016), "Consumers and their behavior: state of the art in behavioral science supporting use phase modeling in LCA and ecodesign", International Journal of Life Cycle Assessment, Vol. 21 No. 2, pp. 237-251. https://doi.org/10.1007/s11367-015-1016-2

Razza, F. et al. (2009), "Compostable cutlery and waste management: An LCA approach", Waste Management, Elsevier Ltd, Vol. 29 No. 4, pp. 1424-1433. https://doi.org/10.1016/j.wasman.2008.08.021

Rossi, V. et al. (2015), "Life cycle assessment of end-of-life options for two biodegradable packaging materials: Sound application of the European waste hierarchy", Journal of Cleaner Production, Elsevier Ltd, Vol. 86, pp. 132-145. https://doi.org/10.1016/j.jclepro.2014.08.049

Vezzoli, C. (2016), Design Di Prodotto per La Sostenibilità Ambientale, 2 edizione, Zanichelli.

Wever, R. et al. (2010), "Influence of Packaging Design on Littering and Waste Behaviour", PACKAGING TECHNOLOGY AND SCIENCE, Vol. 14 No. 16, pp. 165-182. https://doi.org/10.1002/pts

Wikström, F., Williams, H. and Venkatesh, G. (2016), "The influence of packaging attributes on recycling and food waste behaviour - An environmental comparison of two packaging alternatives", Journal of Cleaner Production, Vol. 137, pp. 895-902. https://doi.org/10.1016/j.jclepro.2016.07.097

Wongsriruksa, S. et al. (2012), "The use of physical property data to predict the touch perception of materials", Materials and Design, Vol. 42, pp. 238-244. https://doi.org/10.1016/j.matdes.2012.05.054

Zafarmand, S.J., Sugiyama, K. and Watanabe, M. (2003), "Aesthetic and Sustainability: The Aesthetic Attributes Promoting Product Sustainability", The Journal of Sustainable Product Design, Vol. 3 No. 3-4, pp. 173-186. https://doi.org/10.1007/s10970-005-6157-0

Zuo, H. et al. (2001), "An investigation into the sensory properties of materials", Prooceedings of the 2nd International Conference on Affective Human Factors Design, Ascan Academic Press, London, pp. 500-507. 